\title{
Raw Vs. The Law: Our Fight for Vegetables at the Ottawa-Carleton Detention Centre Erica Brazeau
}

I was incarcerated beginning on 10 May 2020 at the Ottawa-Carleton Detention Centre (OCDC). To my surprise, a lot has changed due to COVID-19. Many changes I agree with, while others I do not. In response to the jail failing to meet many of our most basic rights during the COVID-19 pandemic, I went on a hunger strike on 22 July 2020 along with over 70 prisoners on both the men's and women's sides of the jail (see Figure 1). On the women's side, we demanded an end to strip searches, increased access to hygiene products and food that meets the Canada Food Guide requirements, which the jail is supposed to provide. For me, one of the most important demands was that the jail provides us with fresh fruits and vegetables, which they had failed to do for weeks.

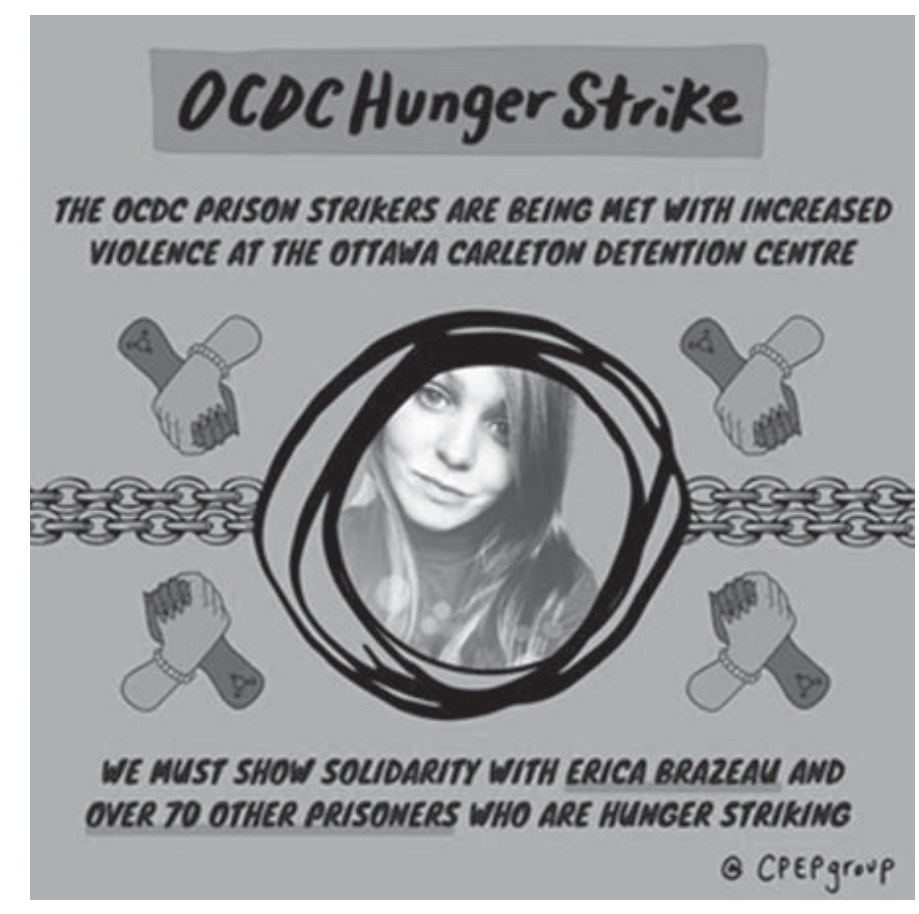

Figure 1:

OCDC Hunger Strike poster by the Criminalization and Punishment Education Project

We need fruits and vegetables in order to maintain a healthy diet, which will help our bodies produce serotonin and raise dopamine levels to keep 
us emotionally well. Usually in jail, I have been able to get a lot of raw vegetables, but this time around I did not get any. We did get the odd serving of carrots, potatoes and peas, but they had been frozen, cooked, and/or steamed using the "cook chill" preparation method, which leaves the vegetables depleted of their nutrients.

For many of us, the importance of eating our fruits and vegetables has been engrained in us since childhood. Most of our parents would not let us leave the dinner table if we did not eat them or take away our dessert. I never imagined I would be in the position of going 10 weeks without one raw vegetable. This left me begging for vegetables. I jokingly tried to make trades with the guards to see if they could find me some vegetables, but to no avail. They kept blaming the lack of fruits and vegetables on COVID-19 because the people in the institution who are normally allowed to prepare trays are no longer allowed to touch the food. This did not make any sense to me because prisoners continue to help out with putting together breakfast trays.

Not being able to eat fresh fruits vegetables week after week created a toxic environment. In the women's dorms, there were many more arguments and girls had issues using the washroom - people felt sick, including myself. From my perspective, if the jail is really trying to keep everyone COVID-19 free, they should not be letting us become malnourished because diet is important for health. Being malnourished puts us at greater risk of illness and disease. During this time, everyone became on edge and was acting moody because we were not eating properly. I feel that prisoners should be allowed to cultivate and maintain a garden to provide essential vegetables rather than feeding us highly processed and nutritionally void food. The food often comes soggy, frozen and/or too spicy.

When we got wind that other prisoners were planning a hunger strike, I decided to get on board from the inside. Unfortunately, it was a disaster and it still bothers me to write about it. Our supporters from the community were rallying outside of the jail to show their support to us. Those of us in the dorms were trying to look out the windows and see what was going on outside. As punishment for watching the protest, the guards took our away our television access and the women I was incarcerated with had their methadone put on hold. The guards held their access to methadone over their heads for watching the protest and teased them like circus animals.

This made me really upset so I stood up for them and they ended up getting their methadone. When they returned, I resumed the protest and asked the 
guards, "How about you guys try go ten weeks without vegetables?" They responded, "Brazeau, shut up or we are moving you". While I understood that the guards could not change things, I expected that they should at least go to their superiors so that they could get the word out. In the end, I was threatened with misconduct. They told me to pack up my stuff and go to maximum security.

It really hurt me having to beg for something that my body needs and getting punished for it, to be treated like my problems were a joke when they were serious. I have moved on to the penitentiary now, but I still wonder how the people are doing at OCDC.

Thankfully, now that I am away from OCDC, I have access to a garden with fruits and vegetables, and I feel so much better after only being at Grand Valley Institution for a month. In provincial jails, the prisoners are being treated poorly, especially considering they have not even been sentenced yet. Prisoners need support and a balanced diet in order to have a good state of mind for release. \#eatgoodfeelgood \#RawVsTheLaw \#FightForVegetables.

\section{ABOUT THE AUTHOR}

Erica Brazeau is an Indigenous writer who is passionate about wellness and making things better for women in prison. She can be reached by mail at the following address:

Erica Brazeau

1575 Homer Watson Blvd.

Kitchener, Ontario

$\mathrm{N} 2 \mathrm{P} 2 \mathrm{C} 5$ 